\title{
A case of meningitis due to varicella zoster virus reactivation in an immunocompetent child
}

\author{
Susanna Esposito ${ }^{*}$, Samantha Bosis, Raffaella Pinzani, Laura Morlacchi, Laura Senatore and Nicola Principi
}

\begin{abstract}
Background: The development of neurological complications due to varicella zoster virus (VZV) reactivation is relatively uncommon, particularly in the case of immunocompetent patients. Only a few cases have been described in the literature, most of which involved adult or elderly patients.

Clinical presentation: Two days after his pediatrician had diagnosed herpes zoster and prescribed oral acyclovir $400 \mathrm{mg}$ three times a day, a 14-year-old boy was admitted to our hospital because of mild fever, severe headache, slowness, drowsiness and vomiting. A cerebrospinal fluid examination was performed and showed an increased protein concentration ( $95 \mathrm{mg} / \mathrm{dL}$ ), normal glucose level (48 mg/dL; blood glucose level, $76 \mathrm{mg} / \mathrm{dL}$ ) and lymphocytic pleocytosis (1,400 lymphocytes/ $\mu \mathrm{L})$, and VZV DNA was detected by means of polymerase chain reaction (1,250 copies/mL). The results of immunological screening for HIV, lymphocyte subpopulation counts, serum immunoglobulin and complement (C3 and C4) levels, vaccine responsiveness and lymphocytes stimulation tests were unremarkable. Acyclovir was administered intravenously at a dose of $10 \mathrm{mg} / \mathrm{kg}$ three times a day and continued for 10 days. The therapy was highly effective and the patient's clinical condition rapidly improved: fever disappeared after two days, and all of the signs and symptoms of neurological involvement after four days. The skin lesions resolved in about one week, and no pain or dysesthesia was ever reported. Given the favourable evolution of the illness, the child was discharged without further therapy after the 10-day treatment. The findings of a magnetic resonance examination immediately after the discontinuation of the antiviral therapy were normal, and a control examination carried out about four weeks later did not find any sign or symptom of disease.

Conclusion: VZV reactivation can also lead to various neurological complications in immunocompetent children. Prompt therapy with acyclovir and the integrity of the immune system are important in conditioning outcome, but other currently unknown factors probably also play a role.
\end{abstract}

Keywords: Herpes zoster, Varicella, Varicella zoster virus, VZV reactivation

\section{Background}

Varicella zoster virus (VZV) is an exclusively human neurotrophic alphaherpesvirus [1]. Primary infection causes varicella (chickenpox), after which the virus becomes latent in ganglionic neurons along the entire neuraxis. With advancing age or immunosuppression, cell-mediated immunity to VZV declines and virus reactivation causes herpes zoster (shingles) which can be complicated by central and peripheral nervous system involvement [2].

The development of the neurological complications of VZV reactivation is relatively uncommon, particularly in the

\footnotetext{
* Correspondence: susanna.esposito@unimi.it

Pediatric Highly Intensive Care Unit, Department of Pathophysiology and Transplantation, Università degli Studi di Milano, Fondazione IRCCS Ca' Granda Ospedale Maggiore Policlinico, Milan, Italy
}

case of immunocompetent patients. Only a few cases have been described in the literature, most of which involved adult or elderly patients [3-8]. Although there is no evidence concerning its efficacy, various antiviral regimens have been prescribed in such cases [2,9], including the administration of antiviral drugs not indicated for the pediatric population.

We here describe the case of an immunocompetent adolescent with herpes zoster and aseptic meningitis due to VZV reactivation because some of the patient's clinical characteristics and the outcome of antiviral treatment make the case interesting.

\section{Case presentation}

A 14-year-old boy was admitted to our hospital because of mild fever (axillary temperature $38^{\circ} \mathrm{C}$ ), severe headache, 
slowness, drowsiness and vomiting. Two days before admission, his parents had noticed a maculopapular rash rapidly evolving into vescicles with an erythematous basis in a very limited region of the left dorsal skin. No other sign or symptom was reported. The patient's pediatrician diagnosed herpes zoster and prescribed oral acyclovir $400 \mathrm{mg}$ three times a day. The boy's medical history was uneventful except for recurrent respiratory infections in his first three years of life. He was diagnosed as having varicella when he was three years old, but did not receive antiviral therapy.

Upon admission, his body temperature was $37.8^{\circ} \mathrm{C}$, vital signs were unremarkable, and the skin lesions located in a small part of the area supplied with C8 were considered consistent with a diagnosis of herpes zoster. At the same time, a neurological examination revealed typical signs and symptoms of meningeal involvement: the patient was slightly confused and unable to tolerate bright light, his deep tendon reflexes were exaggerated, and he was positive for Brudzinski's and Kernig's signs. However, there was no sensory deficit. The results of routine blood examinations were within normal ranges, and there was no increase in inflammatory biomarkers. The findings of brain computed tomography (CT) and electroencephalography examinations were normal. A cerebrospinal fluid (CSF) examination showed an increased protein concentration ( $95 \mathrm{mg} / \mathrm{dL})$, normal glucose level $(48 \mathrm{mg} / \mathrm{dL}$; blood glucose level, $76 \mathrm{mg} / \mathrm{dL})$ and lymphocytic pleocytosis $(1,400$ lymphocytes/ $\mu \mathrm{L}$ ). VZV DNA was detected by means of polymerase chain reaction (PCR, 1,250 copies $/ \mathrm{mL}$ ), whereas the PCR analyses of herpes simplex virus 1 and 2, enterovirus, cytomegalovirus, Epstein Barr virus and JC virus were negative. The results of immunological screening for HIV, lymphocyte subpopulation counts, serum immunoglobulin and complement (C3 and $\mathrm{C} 4$ ) levels, vaccine responsiveness and lymphocytes stimulation tests were unremarkable.

The acyclovir dose was changed to $10 \mathrm{mg} / \mathrm{kg}$ three times a day, which were administered intravenously for 10 days. The therapy was highly effective and the patient's clinical condition rapidly improved: fever disappeared after two days, and all of the signs and symptoms of neurological involvement after four days. The skin lesions resolved in about one week, and no pain or dysesthesia was ever reported. Given the favourable evolution of the illness, the child was discharged without further therapy after the 10-day treatment. The findings of a magnetic resonance examination immediately after the discontinuation of the antiviral therapy were normal, and a control examination carried out about four weeks later did not find any sign or symptom of disease Table 1.

\section{Conclusions}

Herpes zoster mainly affects elderly (its incidence is $8-10$ times higher in people aged $>60$ years than in younger subjects) and immunocompromised patients, including those with acquired immunodeficiency due to drug administration [10], although bone marrow transplant recipients and HIV-seropositive patients are also at particular risk [11]. Waning cell-mediated immunity is thought to be a major factor in the increased incidence of herpes zoster because antibody titres remain unchanged or may even increase with age $[2,11]$, which explains why there are only a few reported cases in immunocompetent children $[1,3]$.

After varicella, VZV remains latent in the sensory dorsal root ganglia and, when reactivated, replicates along the course of the nerve and appears as a vesicular skin rash $[1,2,9]$. In most cases, this is preceded by paresthesia, itching and pain or "pre-herpetic neuralgia" [2,9], and these sensory symptoms can be severe enough to suggest an alternative cause, such as coronary ischemia or an abdominal condition. Pain and itching are the usual concomitants of the eruption, but they can also follow the rash and become chronic but self-limiting "post-herpetic neuralgia" [2,9]. Some atypical cases may lead to pain without any skin lesions, although a significant rise in VZV antibody titres suggests that the pain is closely related to VZV $[2,9,10]$.

The situation in our patient was the opposite: although limited in extent, the skin lesions were clear and easily diagnosed as VZV-related alterations but, surprisingly, they were not associated with any significant pain or dysesthesia throughout the duration of the acute disease or later, including post-herpetic neuralgia. The child had no sensory neurological deficits that could explain the lack of pain in a disease that selectively damages sensory nerves. Consequently, it is reasonable to think that the benign clinical picture was related to the efficiency of his immune system despite the fact that VZV involved the central nervous system while he was receiving antiviral therapy. The positive evolution of the case could also have been due to the prompt acyclovir treatment, whivh is known to be very effective against VZV.

Aseptic meningitis is one of the possible complications of VZV reactivation. It is not one of the most severe neurological complications and usually does not lead to the major brain damage characterising VZV myelopathy, vasculopathy or eye disease [2]. In our case, although the neurological involvement was clinically evident, it was very mild and did not cause any persistent damage, possibly because oral antiviral therapy was started as soon as herpes zoster was diagnosed and, even if it could not have led to high acyclovir concentrations in the CSF, it may have attenuated the severity of the meningitis and favoured a positive clinical outcome. In this regard, this case resembles those recently described by Mantero et al. [4] and Goyal et al. [5], who respectively described VZV meningoencephaloradiculoneuropathy in an immunocompetent young woman with meningitis and cranial palsy and meningitis in a 27-year-old man, both of whom completely recovered. However, these patients received prolonged 
Table 1 Characteristics of an immunocompetent adolescent with herpes zoster and aseptic meningitis due to VZV reactivation

\begin{tabular}{|c|c|}
\hline Characteristics & Data \\
\hline \multicolumn{2}{|l|}{ Demographics } \\
\hline Age & 14 years \\
\hline Gender & Male \\
\hline \multicolumn{2}{|l|}{ Previous history } \\
\hline Age at time of developing varicella & 3 years \\
\hline Clinical problems & Recurrent respiratory tract infections in the first three years of life \\
\hline \multicolumn{2}{|l|}{ Clinical presentation upon admission } \\
\hline Axillary temperature & $37.8^{\circ} \mathrm{C}$ \\
\hline Skin lesions & Dorsal herpes zoster (C8) \\
\hline Neurological symptoms and signs & $\begin{array}{l}\text { Headache, slowness, drowsiness, unable to tolerate bright light, vomiting, stiff neck, } \\
\text { exaggerated deep tendon reflexes, positive Brudzinski's and Kernig's signs }\end{array}$ \\
\hline \multicolumn{2}{|l|}{ Diagnostic examinations upon admission } \\
\hline White blood count & $7,280 / \mu \mathrm{L}$ \\
\hline Lymphocytes & $31.7 \%$ \\
\hline C-reactive protein & $0.10 \mathrm{mg} / \mathrm{dL}$ \\
\hline CSF examination & $\begin{array}{c}\text { Protein } 95 \mathrm{mg} / \mathrm{dL} \text {, glucose } 48 \mathrm{mg} / \mathrm{dL}, 1,400 \text { lymphocytes } / \mu \mathrm{L}, \mathrm{PCR} \text { positive for VZV DNA } \\
1,250 \mathrm{cp} / \mathrm{mL}, \mathrm{PCR} \text { negative for herpes simplex virus } 1 \text { and } 2 \text {, enterovirus, cytomegalovirus, } \\
\text { Epstein Barr virus, JC virus }\end{array}$ \\
\hline Immunological screening & $\begin{array}{l}\text { HIV negative, normal lymphocyte subpopulation counts, normal serum immunoglobulin } \\
\text { and complement levels, vaccine responsiveness and lymphocytes stimulation tests }\end{array}$ \\
\hline Electroencephalography & Normal \\
\hline $\mathrm{CT}$ and $\mathrm{MR}$ & Normal \\
\hline \multicolumn{2}{|l|}{ Antiviral therapy } \\
\hline Oral acyclovir & $400 \mathrm{mg} 3$ times a day for 48 hours (administered at home before neurological involvement) \\
\hline Intravenous acyclovir & 10 mg/kg 3 times a day for 10 days (administered after admission because of meningitis) \\
\hline \multicolumn{2}{|l|}{ Outcome } \\
\hline Duration of fever & 2 days \\
\hline Duration of neurological involvement & 4 days \\
\hline Duration of vescicular eruption & 7 days \\
\hline Duration of hospitalisation & 10 days \\
\hline Clinical evaluation after one month & Normal with absence of neurological involvement \\
\hline
\end{tabular}

CSF: cerebrospinal fluid; CT: computed tomography; MR: magnetic resonance; PCR: polymerase chain reaction; VZV: varicella zoster virus.

acyclovir therapy, whereas our patient required only 10 days of intravenous treatment. Further information should be collected concerning when and how long antiviral treatment should be administered to patients with neurological involvement due to VZV reactivation.

The findings of the immunological examinations of our child were normal, but a normal immune system does not guarantee the benign course of the neurological manifestations of VZV reactivation. Mpaka et al. have described the case of a previously healthy 66-year-old man whose obtundation deteriorated to coma within 24 hours of disease onset [6] after the development of lymphocytic meningitis with multiple, bilateral edematous and hemorrhagic lesions predominantly in the white matter, and intraventricular and subarachnoid hemorrhaging. The diagnosis of VZV encephalitis was confirmed by PCR analysis of the CSF, and he received adequate treatment with acyclovir. However, although his general condition was considered good two years later, this case shows that meningitis induced by VZV reactivation can have a complicated evolution even in immunocompetent subjects.

Our case underlines the fact that VZV reactivation can also lead to various neurological complications in immunocompetent children, which may be benign (as in our case) or very severe $[2,10]$. Prompt therapy with acyclovir and the integrity of the immune system are important in conditioning outcome, but other currently unknown factors probably also play a role. Further studies are needed to clarify the relationships between VZV and neural damage. 


\section{Consent}

Written informed consent to the publication of this case report and any accompanying images was obtained from the patient's parents. A copy of the written consent is available for review by the Editor of the journal.

\section{Abbreviations \\ CSF: Cerebrospinal fluid; CT: Computed tomography; MR: Magnetic resonance; PCR: Polymerase chain reaction; VZV: Varicella zoster virus.}

\section{Competing interests}

The authors declare that they have no competing interests.

\section{Authors' contributions}

SE drafted the manuscript, supervised the management of the clinic, and was head of the pediatric clinic in which the patient was hospitalised; SB, RP, LM and LS admitted the patient, followed him during hospitalisation, and carried out the follow-up examinations; NP co-wrote the draft manuscript All of the authors read and approved the final version of the manuscript.

\section{Acknowledgements}

This study was supported by a grant from the Italian Ministry of Health

(Bando Giovani Ricercatori 2009).

Received: 16 October 2013 Accepted: 11 November 2013

Published: 13 November 2013

\section{References}

1. Pahud BA, Glaser CA, Dekker CL, Arvin AM, Schmid DS: Varicella zoster disease of the central nervous system: epidemiological, clinical, and laboratory features 10 years after the introduction of the varicella vaccine. J Infect Dis 2011, 203:316-323.

2. Nagel MA, Gilden D: Complications of varicella zoster virus reactivation. Curr Treat Options Neurol 2013, 5:439-453.

3. Han JY, Hanson DC, Way SS: Herpes zoster and meningitis due to reactivation of varicella vaccine virus in an immunocompetent child. Pediatr Infect Dis J 2011, 30:266-268.

4. Mantero V, De Toni Franceschini L, Lillia N, Guccione A, Santilli I, Agostoni E: Varicella-zoster meningoencephaloradiculoneuropathy in an immunocompetent young woman. J Clin Virol 2013, 57:361-336.

5. Goyal H, Thakkar N, Bagheri F, Srivastava S: Herpes zoster meningitis with multidermatomal rash in an immunocompetent patient. Am J Emerg Med 2013. Epub Jul 25.

6. Mpaka M, Karantanas AH, Zakynthinos E: Atypical presentation of varicella-zoster virus encephalitis in an immunocompetent adult. Heart Lung 2008, 37:61-66.

7. Kangath RV, Lindeman TE, Brust K: Herpes zoster as a cause of viral meningitis in immunocompetent patients. BMJ Case Rep 2013. Epub Jan 9

8. Nahdi I, Boukoum H, Nabil Ben Salem A, Ben Romdane F, Hammami S, Chebel S, Mahbouba FA, Guediche MN, Chakroun M, Aouni M, Imbert-Marcille BM, Bressollette-Bodin C: Detection of herpes simplex virus (1 and 2), varicella-zoster virus, cytomegalovirus, human herpesvirus 6 and enterovirus in immunocompetent Tunisian patients with acute neuromeningeal disorder. J Med Virol 2012, 84:282-289.

9. Baird NL, Yu X, Cohrs RJ, Gilden D: Varicella zoster virus (VZV)-human neuron interaction. Viruses 2013, 5:2106-2115.

10. Gilden D, Nagel MA, Cohrs RJ, Mahalingam R: The variegate neurological manifestations of varicella zoster virus infection. Curr Neurol Neurosci Rep 2013, 13:374.

11. Gershon AA, Gershon MD, Breuer J, Levin MJ, Oaklander AL, Griffiths PD: Advances in the understanding of the pathogenesis and epidemiology of herpes zoster. J Clin Virol 2010, 48(Suppl 1):S2-S27.

doi:10.1186/1824-7288-39-72

Cite this article as: Esposito et al:: A case of meningitis due to varicella zoster virus reactivation in an immunocompetent child. Italian Journal of Pediatrics 2013 39:72.

\section{Submit your next manuscript to BioMed Central and take full advantage of:}

- Convenient online submission

- Thorough peer review

- No space constraints or color figure charges

- Immediate publication on acceptance

- Inclusion in PubMed, CAS, Scopus and Google Scholar

- Research which is freely available for redistribution 